\title{
Background seismicity and seismic monitoring in the Lai Chau reservoir area
}

\author{
Grzegorz Lizurek (D) - Jan Wiszniowski • N. V. Giang • D. Q. Van • L. V. Dung • \\ V. D. Tung • Beata Plesiewicz
}

Received: 20 December 2018 / Accepted: 12 September 2019/Published online: 25 October 2019

(C) The Author(s) 2019

\begin{abstract}
Reservoir-triggered seismic activity depends not only on the technical characteristics of the future reservoir (filling volume, the height of water column) but also on the seismo-tectonics and the natural seismic processes occurring in the area before construction of an artificial reservoir. Passive seismic monitoring was realised near Lai Chau (Vietnam) before the impoundment started. It allowed exploration of the natural seismicity in the area of the future dam. Locations of seismic events several months prior to the reservoir impoundment were observed with ten stations installed in the reservoir vicinity. Events were mainly located near the dam along the Da river headwaters fault. However,
\end{abstract}

Electronic supplementary material The online version of this article (https://doi.org/10.1007/s10950-019-09875-6) contains supplementary material, which is available to authorized users.

G. Lizurek $(\bowtie) \cdot J$. Wiszniowski $\cdot$ B. Plesiewicz Institute of Geophysics Polish Academy of Sciences, Księcia Janusza 64, 01-452 Warszawa, Poland

e-mail: lizurek@igf.edu.pl

\section{N. V. Giang}

Binh Duong University, 504 Binh Duong Avenue, Hiep Thanh Ward, Thu Dau Mot, Binh Duong, Vietnam

URL: https://www.bdu.edu

N. V. Giang • D. Q. Van • L. V. Dung

Institute of Geophysics, VAST, A8, 18 Hoang Quoc Viet,

CauGiay, Hanoi, Vietnam

V. D. Tung

Institute of Geological Sciences, VAST, 84 Chua Lang, Dong Da, Hanoi, Vietnam only four stations were available for the entire period before the impoundment. Despite the network limitations, completeness of seismic catalogue and $b$ value were determined and may be used as a baseline for analysis of the seismicity in this area after impoundment. The magnitude completeness level is significantly smaller than in the broader seismogenic zones covering an area of the dam. The $b$ value differs from the results obtained for regional seismicity of Northeastern Vietnam. The capability of the local network for moment tensor inversion was estimated with the use of synthetic data tests. Test results provided the requirements for the station number according to azimuthal coverage of the network to obtain the reliable full moment tensor (MT) solution. Preliminary analysis of the seismic activity after Lai Chau reservoir impoundment indicates some changes in activity related to the impoundment and reservoir exploitation.

Keywords Reservoir-triggered seismicity · Moment tensor $\cdot$ Seismic monitoring $\cdot$ Background seismicity

\section{Introduction}

Due to the growing need for electricity in developing countries such as Vietnam, Laos and Cambodia, hydropower projects in southeastern Asia have been booming for the last 10 years and several tens of such projects are being implemented or planned. The hydropower stations are currently producing about $30 \%$ of all electricity 
in Vietnam. The impoundment of surface reservoirs has triggered the anthropogenic seismic events causing significant material loss, injuries and fatalities. The strongest earthquake ever, triggered by water impoundment, was the damaging 6.3 magnitude event near the Koyna Dam, India, in December 1967 (Gupta 2002). The role of reservoir exploitation in triggering of tragic 7.9 magnitude earthquake in China 2008 is still a matter of debate (Ge et al. 2009; Gahalaut and Gahalaut 2010). In Vietnam, the strongest case of a reservoir-triggered seismic event of magnitude 4.9 occurred in the Hoa Binh Province, Northern Vietnam, in 1989 (Tung 1996). However, reservoir-triggered seismicity (RTS) was also observed in Central Vietnam (e.g. Wiszniowski et al. 2015; Lizurek et al. 2017). Apart from some exceptions, where a seismic station existed, or the project managers had the foresight to install seismographs before filling reservoirs, welldocumented variations of the regional seismicity due to the impoundment of reservoirs are rare. Seismic stations were commissioned only in the case once seismic activity started subsequently to the impoundment (Gupta 1992). The dam in the Lai Chau region gives a unique chance to carry out seismic measurements due to the moderate natural seismicity in the area (e.g. Pailopee and Choowong 2014; Lu et al. 2017). It also gives a possibility of observing the anthropogenic seismicity in the region. One regional station and a local network of four stations had been installed in the area before the impoundment started. Then, another few stations were installed, which currently form the network of ten stations in the vicinity of the dam with two broadband supporting stations in the close distance. The detailed local seismicity monitoring has been available since October 2014. The Lai Chau reservoir impoundment started in June 2015. Thus, it allowed thorough monitoring of the reservoir vicinity for at least several months before reservoir-triggered seismic activity started. Within this work, we focused on the background seismicity of the Lai Chau area and the capabilities of the local network for moment tensor (MT) inversion. The completeness magnitude and $b$ value of the background seismicity were determined before the reservoir impoundment. The seismic network was described and the capability of the MT inversion was tested. The test provided the requirements for the station number, according to azimuthal coverage of the network to obtain the reliable full MT solution. Preliminary analysis shows a decrease of the seismic activity and $b$ value directly after the impoundment of the reservoir, until October 2016. Then activity and $b$ value increased and reached the highest values since the beginning of the observations. It may indicate the influence of the reservoir on the seismicity on active faults.

\section{Seismic network in Lai Chau area}

The area of Lai Chau dam was planned to be monitored by the local network of at least ten seismic stations. The network has been developed gradually, due to nonsubstantial reasons, which made the planned, simultaneous installation of all stations impossible. In the beginning, the seismicity of Lai Chau region was monitored by Vietnamese National Stations Network. There were seven stations in North Vietnam, with Điện Biên (DBVB) station $80 \mathrm{~km}$ from the Lai Chau region. The station in the $\mathrm{Sa}$ $\mathrm{Pa}$ (SPV), which has been operating since 1957, was located $90 \mathrm{~km}$ from the region, both too far to be included in Fig. 1. Only the station in the Mường Lay (MLAV) was located in the Lai Chau region, $16 \mathrm{~km}$ from the dam (Fig. 1). The IGP VAST set up a number of local stations dedicated to monitoring the area of Lai Chau reservoir. Three stations in NậmNhùn (NNU), Chà Cang (CCA) and MườngTè (MTE) were installed in September 2014 and one station Nậm Na 3 (NNU3) - at the beginning of filling in the reservoir in June 2015. Next stations in Chăn Nưa (CNUD), Pú Đao (PUDD), Kan Hồ (KHOD) and Hua Bum (HUBD) were launched by the IG PAS in July 2016, after the reservoir had been filled up. The last station in Mường Mô (MMOD) was activated in June 2017. Locations and parameters of stations are presented in Table 1 and Fig. 1.

The responses of recording systems are presented in the electronic supplement. Very broadband (Fig. ES1a), broadband (Fig. ES1b and Fig. ES1c) and short period (Fig. ES1d) sensors were used. All stations have a sampling rate of 100 samples per second. Positions of stations are determined by the location of the previous seismic events and by a desire of providing good horizontal coverage for events around the dam. It should help in more accurate estimation of the moment tensor of reservoir-triggered events. However, the location of the station was strongly limited by logistic possibilitiespoor urbanisation and a small number of roads in this area. Additionally, stations had to be located in residential areas for security reasons. Therefore, the western part of the reservoir is poorly covered with stations (Fig. 1). The 

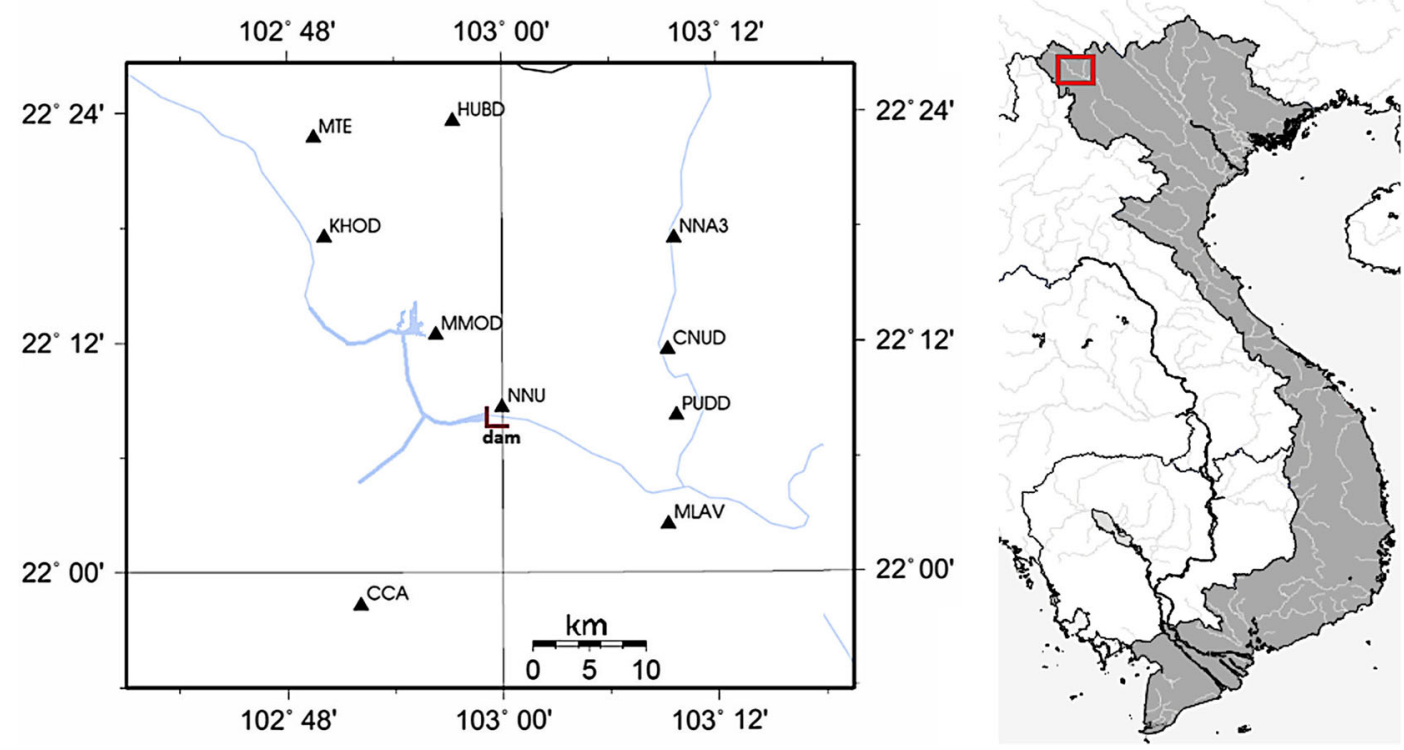

Fig. 1 Stations (black triangles) of the local network in Lai Chau reservoir area

detailed location of stations was preceded by groundpenetrating radar (GPR) measurements (Giang et al. 2010) in order to find the foundation of stations on the uncracked bedrock. It allowed reducing both natural and human noise and improving detection of seismic events. Seismic noises of stations in the Lai Chau region are presented in Fig. 2. It should be noticed that not all stations worked all the time. Differences in noise between day and night as well as between dry and wet seasons have not been noticed.

\section{Tectonic activity and background seismicity}

The studied region located near Mường Tè belongs to SouthEast Asia, where North Vietnam's westernmost continental block is called Sibumasu or Shan-Thai. The Southern Chinese continent block is located to the northeast, whereas the continental block Indochina is located to the southeast, and the boundary of the two continental blocks is the strike-slip Red River zone and Lai Chau-Điện Biên fault zone. These two large-scale

Table 1 Seismic stations in the Lai Chau area

\begin{tabular}{lllllll}
\hline \multirow{2}{*}{ No. } & Station name & Code & Coordinates & & \multirow{2}{*}{ Elevation [m] } & Datalogger/seismometer \\
\cline { 5 - 6 } & & & Latitude $\left[{ }^{\circ} \mathrm{N}\right]$ & Longitude $\left[{ }^{\circ} \mathrm{E}\right]$ & & Q330HR/STS-2 \\
\hline 1 & Điện Biên & DBVB & 21.3900 & 103.0184 & 493 & Q330HR/STS-2 \\
2 & Sa Pa & SPV & 22.2367 & 105.3505 & 1021 & Q330HR/STS-2 \\
3 & Mường Lay & MLAV & 22.0419 & 103.1538 & 209 & CMG-6TD \\
4 & Nậm Nhùn & NNU & 22.1436 & 102.9997 & 300 & CMG-6TD \\
5 & Mường Tè & MTE & 22.3790 & 102.8245 & 319 & 801H/CMG-40T \\
6 & Nậm Na 3 & NNA3 & 22.2909 & 103.1602 & 278 & CMG-6TD \\
7 & Chà Cang & CCA & 21.9712 & 102.8682 & 454 & GMSplus/VE-53BB \\
8 & Chăn Nưa & CNUD & 22.1938 & 103.1538 & 235 & GMSplus/VE-53BB \\
9 & Pú Đao & PUDD & 22.1364 & 103.1619 & 743 & GMSplus/VE-53BB \\
10 & Mường Mô & MMOD & 22.2072 & 102.9381 & 383 & GMSplus/VE-53BB \\
11 & Can Hồ & KHOD & 22.2919 & 102.8343 & 388 & GMSplus/VE-53BB \\
12 & Hua Bum & HUBD & 22.3932 & 102.9537 & 577 & \\
\hline
\end{tabular}



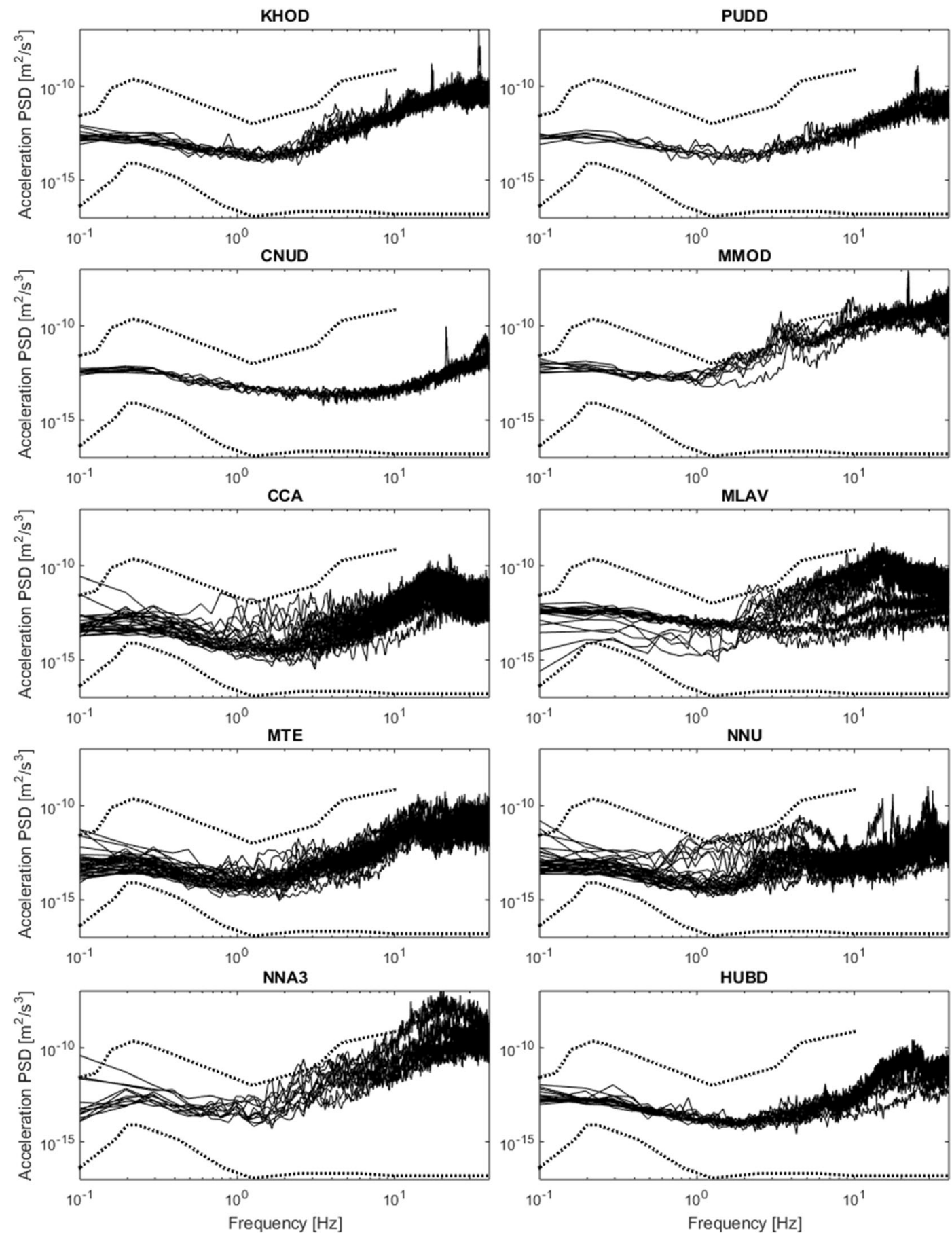

Fig. 2 The Power spectral densities (PSD) of seismic noise in network stations in the Lai Chau area. The lines are the PSD of Peterson's (Peterson 1993) New Low Noise Model and New High Noise Model

fracture zones are active, resulting in the shift of important structural blocks adjacent to their borders (Aihara et al. 2007; Brookfield 1996; Bach and Tam 2008; Hoa et al. 2008; Tong et al. 2013; Yang et al. 1995; Sato et al.
2007). Main fault zones connected with seismic activity are Da river headwaters fault, Mường Tè fault, Nam Nho-Nam Cuoi fault and Lai Chau - Điện Biên fault (Fig. 3). The strongest earthquakes $(M>5)$ were located 


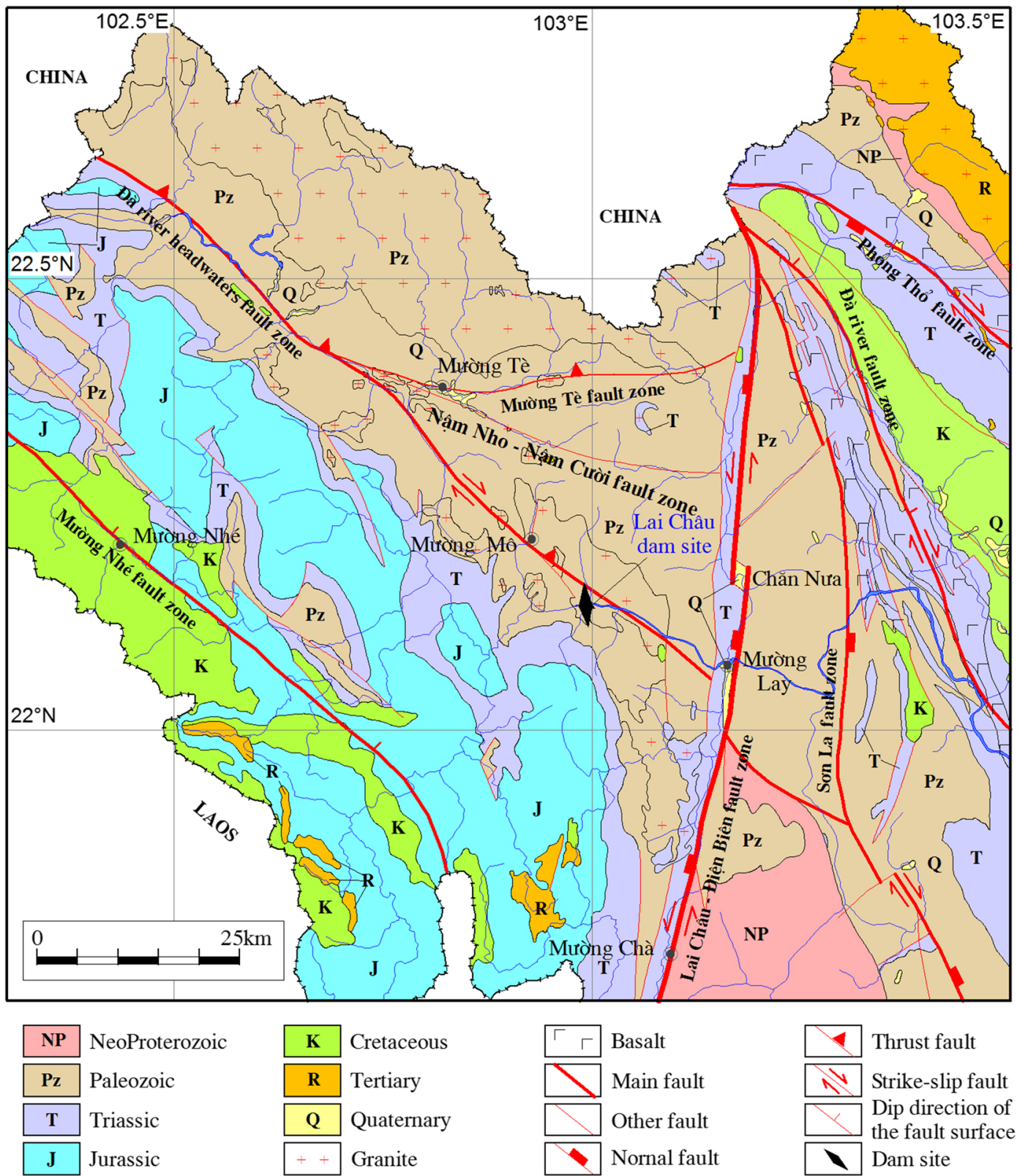

Fig. 3 Map of geological structure and tectonic characteristics for the Lai Chau region

in Lai Chau-Điện Biên fault zone: moderate seismicity $(4<M<4.6)$ was observed in Da river headwaters and Nam Nho-Nam Cuoi fault zones. The smallest seismic events were observed $(3.6<\mathrm{M}<4)$ in Mường Tè fault zone, located in the vicinity of Lai Chau dam and the reservoir. (Pho 2000; Thang and Tung 2006; Tung 2011).

As mentioned above, the northern part of Vietnam is characterized by moderate regional seismic activity with the strongest events up to M5.6. We define here background seismicity (BS) as the tectonic seismicity recorded before the reservoir filling have started that is located in the vicinity of the planned reservoir. Therefore, the BS is not all regional seismicity observed up to several tens of kilometres away from the reservoir. Within 8 months before the impoundment of the reservoir, which started in June 2015, 184 events were detected by the network of four stations: CCA, MLAV, MTE and NNU. As the local 
network was not fully operational at that time, many weak events were recorded only by one station and could not be located. The local magnitude calculations were based on Richter's (1936) magnitudes obtained from S-waves of the Wood-Anderson seismometer simulations, with the original Richter's (1958) distance correction term.

The location of the events was calculated with onedimensional P-wave and S-wave velocity model of the northern part of the North West Region of Vietnam (Fig. 4) developed by Son et al. (2012). The LocSat algorithm was used for seismic events location (Bratt and Bache 1988). Origin time, epicentre location and depth were estimated from an iterative least-squares inversion of travel time of phases $\mathrm{Pg}$ and $\mathrm{Sg}$, which were picked manually. The travel-time tables were calculated from the onedimensional velocity model (Fig. 4). Most of the located events have residuals less than $0.1 \mathrm{~s}$. Only events located outside the network have high residual values that is most likely caused by inaccurate 1D local velocity model in comparison with real $3 \mathrm{D}$ velocity field on the regional scale.

From October 2014 to June 2015, among 184 events detected, only 97 were strong enough to be located. They were located mainly along the $\mathrm{Da}$ river headwaters fault and the Lai Chau-Dien Bien fault (Fig. 5), but most of the events were located in the vicinity of the dam.

The completeness of catalogues has been estimated based on 97 events having magnitude $M_{\mathrm{L}}=0.3 \div 3.1$, that were situated in the Lai Chau area. The unbounded Gutenberg-Richter (G-R) model of the frequencymagnitude distribution (FMD) was assumed (Fig. 6). The completeness magnitude $\left(M_{\mathrm{c}}\right)$ of the background seismicity was estimated using a few catalogue-based methods (Leptokaropoulos et al. 2013). The first one was the maximum curvature method (Wyss et al. 1999; Wiemer and Wyss 2000) and goodness-of-fit (GFT) test methods (Wiemer and Wyss 2000), where the minimum magnitude $M_{\mathrm{i}}$ is fitted for events with $M \geq M_{\mathrm{i}}$ by the application of maximum-likelihood estimation. It allows for perfect fitting of the synthetic data with the power law of the distribution of magnitudes. The difference between the cumulative number of observed events $N_{0}$ and simulated events $N_{\mathrm{S}}$ in each magnitude bin is then computed and mapped according to the following formula:

$D=\frac{\sum_{M_{i}}^{M_{\max }}\left|N_{0}-N_{S}\right|}{\sum_{i} N_{0}}$,

where $M_{\max }$ is the maximum magnitude in the catalogue. If the dataset above a specific magnitude $M_{\mathrm{i}}$ is incomplete, the value of $D$ will be high. A model is then found for a $D$ value, at which a predefined percentage-usually 90\% (Table 2 No. 2) or $95 \%$ (Table 2 No. 3 ) of the observed data is covered. Leptokaropoulos et al. (2013) modified the goodness-of-fit test. In their method (Table 2 No. 4), synthetic datasets of $N_{\mathrm{i}}$ events, where $N_{i}$ is the cumulative number of events with $M \geq M_{\mathrm{i}}$, are created by distributing random numbers according to the respective G-R law (Zechar 2010). The process is repeated $k$ times and $k$ synthetic catalogues are created. The $k$ was chosen to 500 . Starting from the minimum magnitude $M_{\mathrm{i}}=0.3$, parameters $a$ and $b$ of the G-R law are computed following maximum-likelihood estimation for all
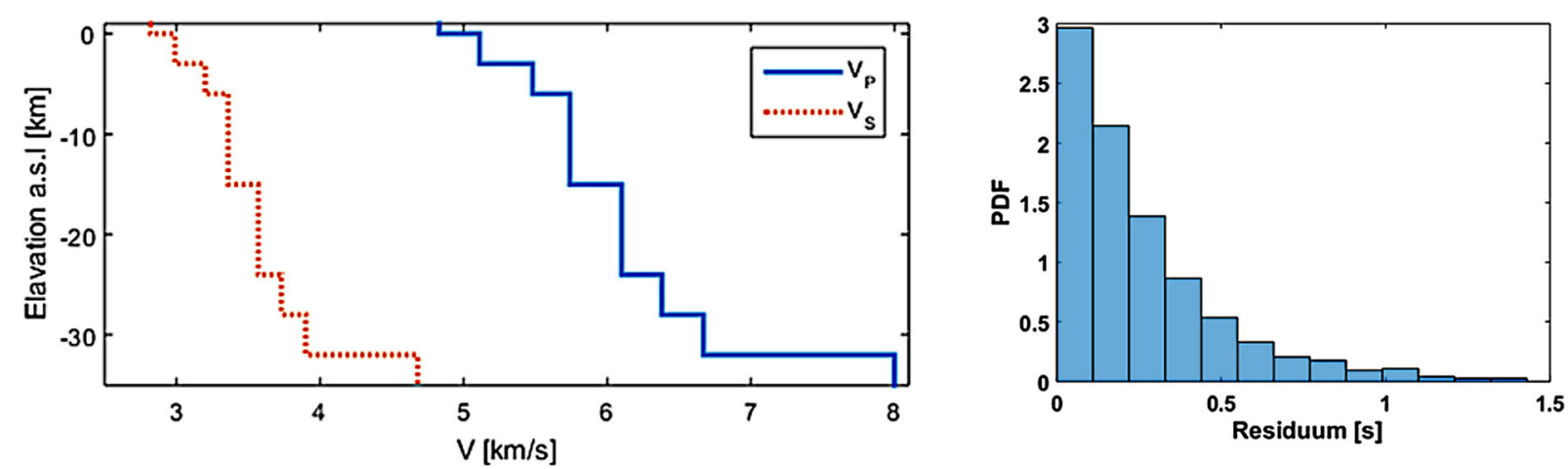

Fig. 4 One-dimensional velocity model for the Lai Chau region (left) and the probability density function of LocSat location time residuals (right) 


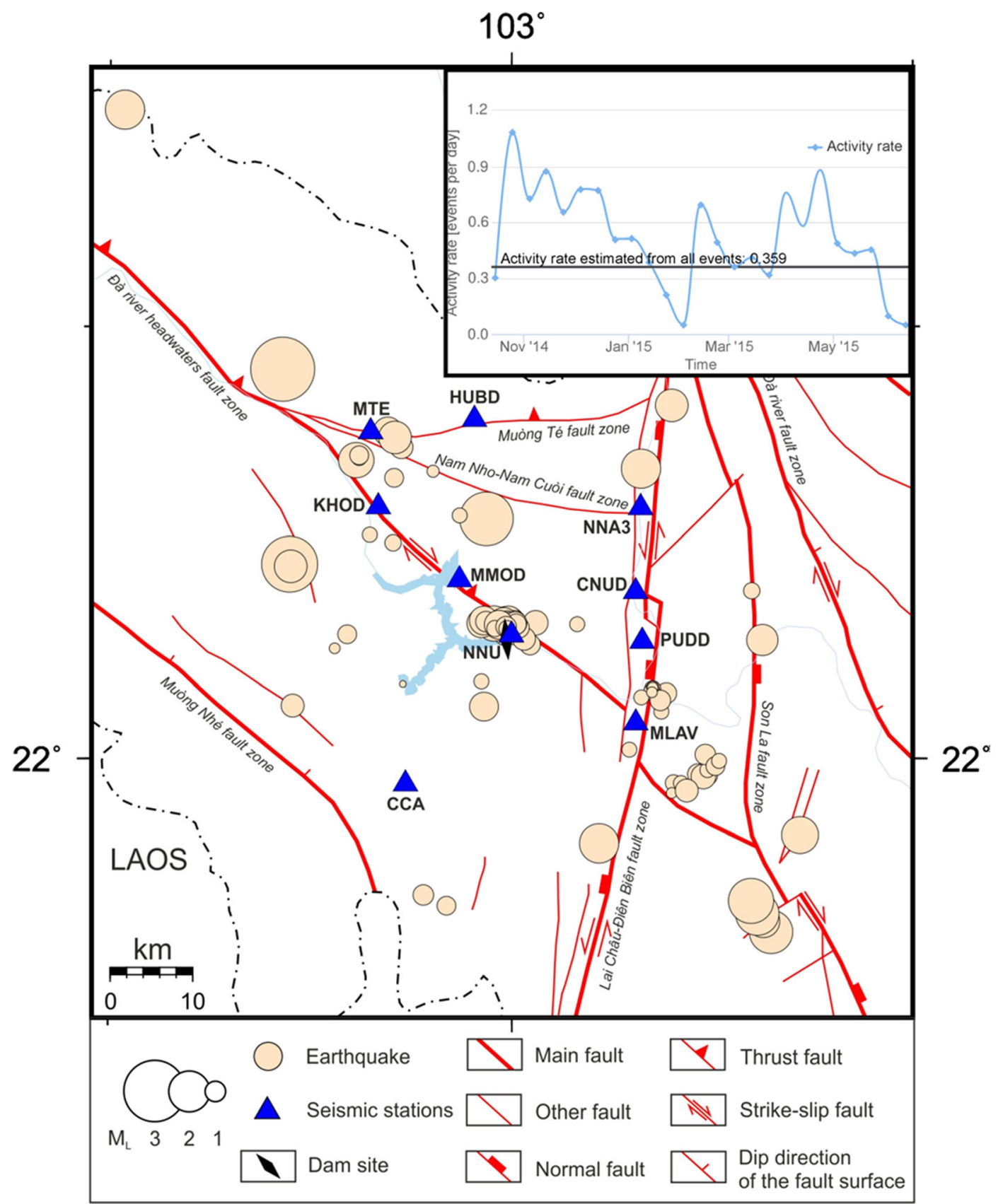

Fig. 5 Location of tectonic events recorded in the Lai Chau region and activity rate plot in the period from October 2014 to June 2015

events with $M_{\mathrm{i}} \leq M$. The $\mathrm{b}$ value is estimated according to Aki (1965), with Leptokaropoulos et al. (2013) expressing $b$ value accuracy $\sigma_{\mathrm{b}}$ as

$$
\sigma_{b}=\frac{b}{\sqrt{N}}
$$

where $N$ is the number of samples (Fig. 7). The difference between each of these synthetic and observed datasets is calculated following Eq. (1). Then, the whole procedure is repeated for $M_{\mathrm{i}+1}$. The results of the above four procedures are similar (Table 2), whereas $b$ values and $b$ errors for $M_{\mathrm{i}}$ in range $0.7 \div 0.9$ are presented in Table 3 . 


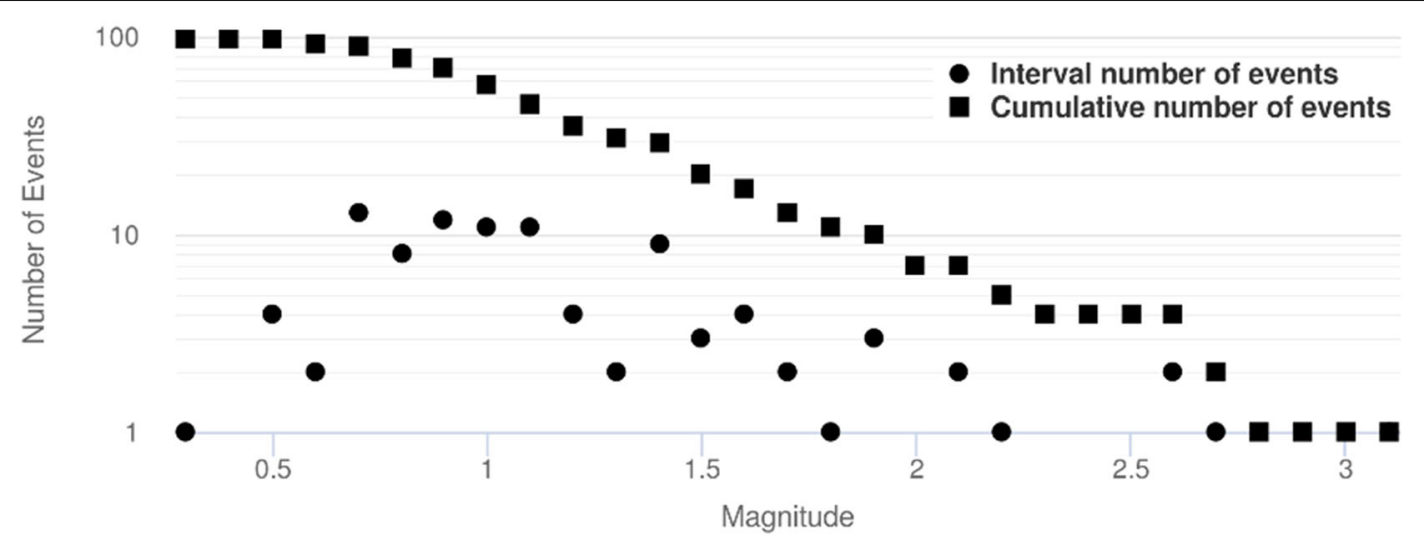

Fig. 6 Number of events recorded in the Lai Chau region before filling the dam vs $M_{\mathrm{L}}$ bins

\section{Moment tensor inversion capabilities of Lai Chau network}

Focal mechanism and MT are crucial parameters in the interpretation of anthropogenic seismicity. They allow tracking the main discontinuities and stress orientation in the area of anthropogenic seismicity. If full MT is reliably obtained, it may help in the distinction between triggered or induced seismic process (Dahm et al. 2013). The possibility of the dense station locations in the Lai Chau area was limited resulting in poor azimuthal coverage on the western part of the lake. However, in such case, moment tensor may be calculated using inversion of the P-wave amplitudes and polarities in the time domain using focimt software (Wiejacz 1992; Kwiatek and Martinez-Garzon 2016). The recorded displacement for the P-wave phase is:

$\mathrm{U}^{P}(\mathrm{x}, t)=\frac{\gamma \cdot \dot{\mathrm{M}}\left(\mathrm{t}-\frac{r}{\alpha}\right) \cdot \gamma}{4 \pi \rho \alpha^{3} r} 1$,

where $\rho$ is the average medium density, $r$ is the sourcereceiver distance, $\alpha$ is the average velocity of the P-wave,

Table 2 Results of completeness magnitude estimations

\begin{tabular}{llc}
\hline No. & The $M_{\mathrm{c}}$ estimation method & $M_{\mathrm{c}}$ \\
\hline 1 & Maximum curvature method & 0.7 \\
2 & The goodness-of-fit test at 90\% confidence bounds & 0.7 \\
3 & The goodness-of-fit test at 95\% confidence bounds & 0.9 \\
4 & Modified goodness-of-fit test & 0.7 \\
\hline
\end{tabular}

$M$ is the seismic moment tensor, $l$ is the $\mathrm{P}$-wave direction at the receiver and $\gamma$ is the P-wave direction at the source according to Fitch et al. (1980), De Natale et al. (1987) and Aki and Richards (2002). The measured amplitude and polarity of first P-wave onset, P-wave velocity, take-off angle and incidence angle derived from local $1 \mathrm{D}$ velocity model hypocentral distance as source-receiver distance are used as input values for inversion. Incidence and take-off angles are calculated with focimt software following 1D velocity model ray-tracing routines from hypoDD v1.3 package (Waldhauser 2001). Moment tensor is obtained by solving a set of $N$ equations of type (3), where $N$ is the number of stations that recorded the event. Six independent components of moment tensor require a minimum of six equations, but the more the better. In the case of Lai Chau network, up to 12 stations could be available, but only ten of them are reasonably close to the lake, so they could be useful in case of weak $M<2$ events related to the reservoir exploitation. The system of Eq. (3) is overdetermined and solved for using a least-squares approach (L2 norm) with the cost function being the sum of squares of residuals. When the condition of the zero trace is imposed on the solution, the deviatoric moment tensor may be determined excluding mechanism with a volumetric change in the source. When the conditions of the zero trace and zero determinant are set, the solution is limited to the doublecouple source. The full moment solution can also be decomposed into the isotropic (ISO), compensated linear vector dipole (CLVD) and double-couple (DC) parts of the mechanism following the default decomposition scheme of Knopoff and Randall (1970), with percentage of decomposed tensor elements calculated by either Knopoff and Randall (1970) or Vavryčuk (2001, 2015). This 


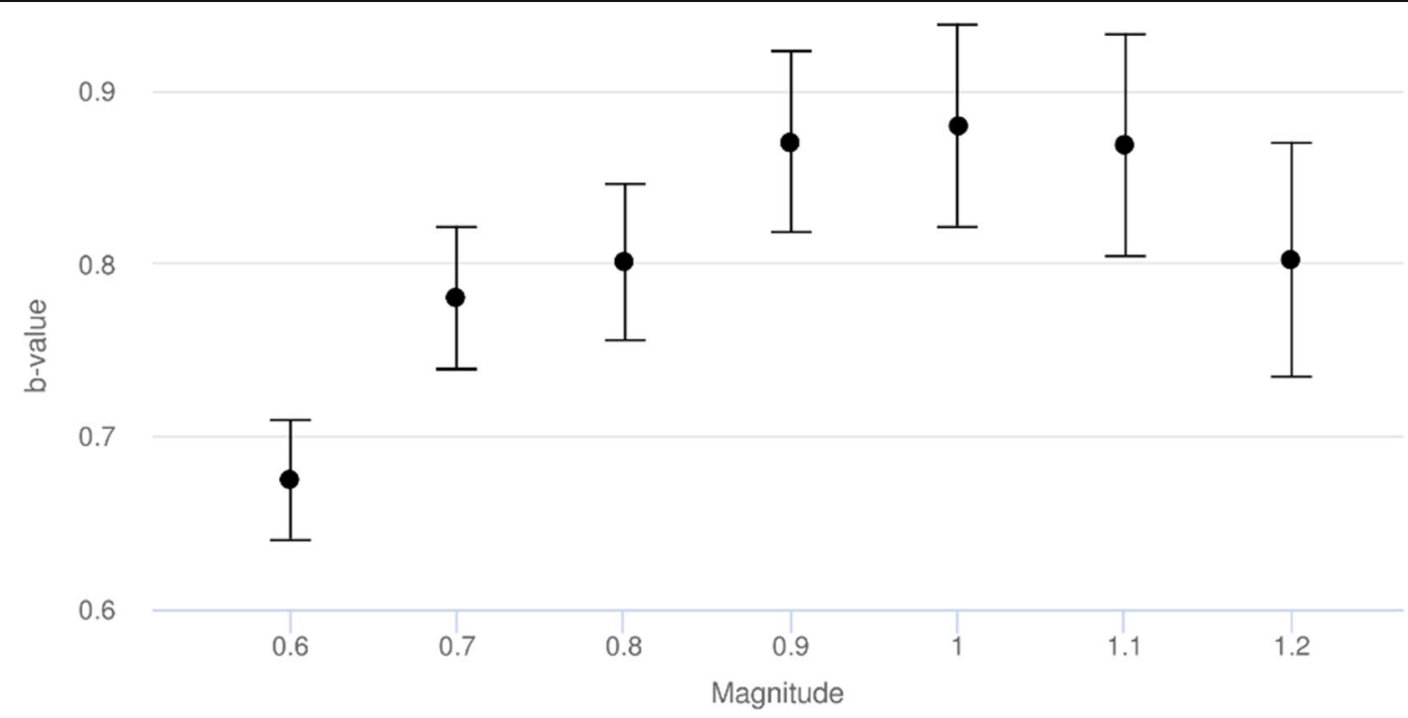

Fig. 7 The $b$ value of the G-R FMD end $b$ error vs magnitude $M_{\mathrm{L}}$ bins

decomposition usually shows the complexity of the source process and is used to check the quality of the solution (Wiejacz 1992). Uncertainties of the estimated moment tensors can be assessed by the normalised root-meansquare (RMS) error between theoretical and measured amplitudes (Stierle et al. 2014a, b):

$R M S=\sqrt{\frac{\sum_{i=1}^{N}\left(U_{i}^{\text {measured }}-U_{i}^{\text {th }}\right)^{2}}{\sum_{i}^{N}\left(U_{i}^{\text {measured }}\right)^{2}}}$

The synthetic tests of the network capabilities in MT inversion, calculated using the above-described method, are useful in the context of planning further analysis of the seismicity. The tests are developed assuming the locations of seismic events are similar to those already observed: one type in the middle of the network, close to the artificial lake and another at the edge of the network. In both cases, normal faulting with an orientation similar to main

Table 3 Results of $b$ value estimations

\begin{tabular}{llll}
\hline & \multicolumn{3}{l}{$\begin{array}{l}\text { Completeness } \\
\text { magnitude } M_{\mathrm{c}}\end{array}$} \\
\cline { 2 - 5 } & 0.7 & 0.8 & 0.9 \\
\hline$b$ value & 0.780 & 0.801 & 0.870 \\
$b$ value error & 0.082 & 0.091 & 0.105 \\
Mean activity rate above the $M_{\mathrm{c}}$ [events per day] & 0.337 & 0.288 & 0.258 \\
\hline
\end{tabular}

discontinuity located in the dam area $\left(143^{\circ} / 82^{\circ} /-\right.$ $88^{\circ}$ ) and pure shearing in point source were assumed for generating input data (amplitudes and polarities of the P-wave displacements). Synthetic amplitudes and polarities were generated for a priori known fault orientations. The mechanism for the synthetic data was assumed as pure shearing $(99.99 \%$ of the DC full MT component). The synthetic input data were: amplitude and polarities of P-wave displacement. They were simulated following the proper focal sphere quadrants to the configuration and by the $\mathrm{P}$ and $\mathrm{T}$ axes orientations of the assumed fault. Bootstrap amplitude resampling tests of noise was prepared to check, to what extent possible noise can influence the MT inversion results. Then take-off angle uncertainty test was aimed at checking how the velocity model uncertainties influence the solutions. Finally, the third test was run to verify azimuthal gap influences, simulated by the removal of a single station from the input data. The number of bootstrap samples was set at 100 . All the synthetic input data and further analyses were carried out with the use of focimt software (Kwiatek and MartinezGarzon 2016), based on P-wave polarity and amplitude displacement in MT inversion. The RMS error of all MT solutions for these synthetics was smaller than 0.01 . Due to the sparse network before the filling up of the reservoir and 1D velocity model available, the depth of the events is not well 


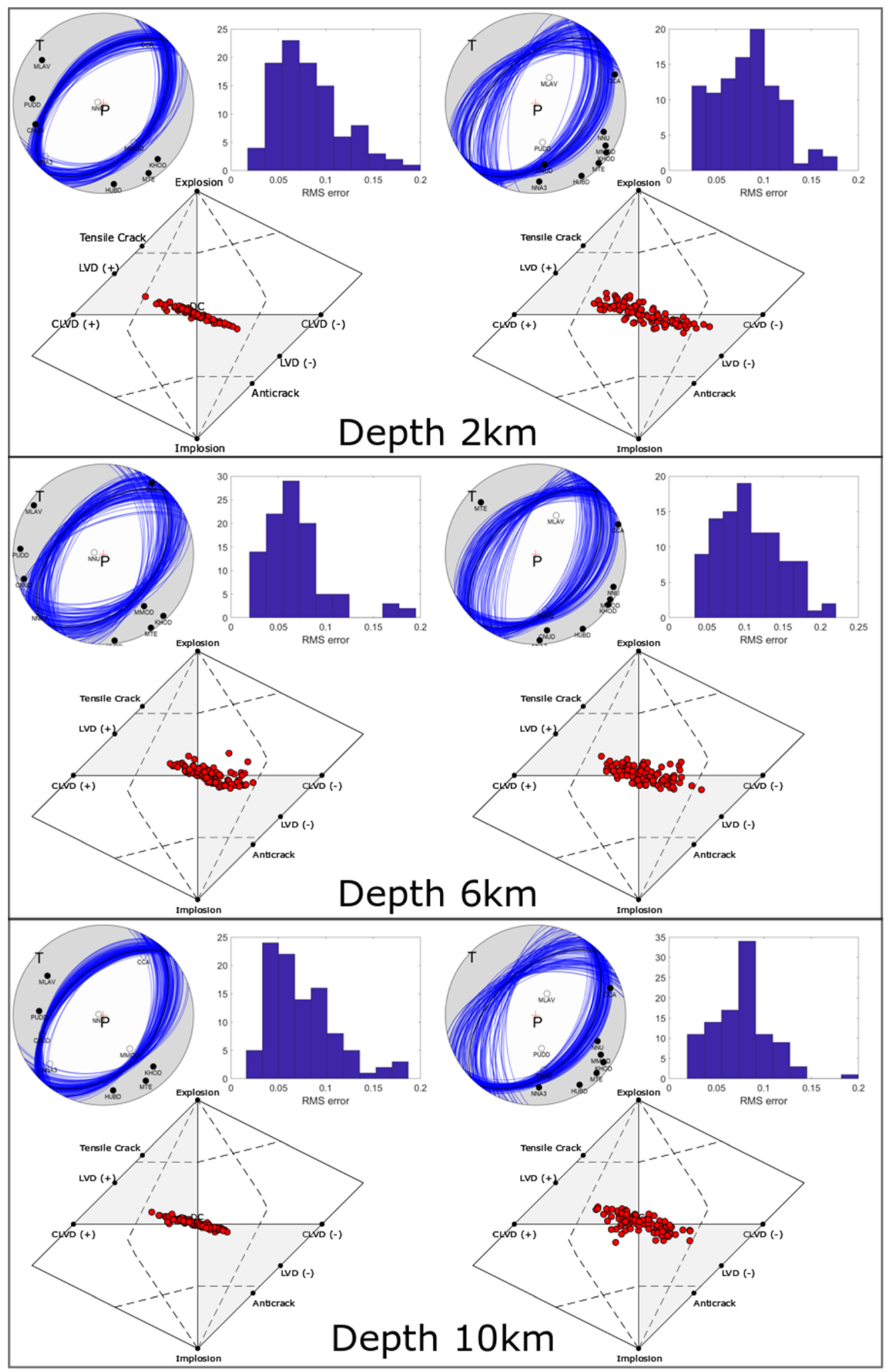


Fig. 8 Results of the noise influence on MT inversion for Lai Chau network for two epicentre and three depth locations. On the left side - good focal sphere coverage (event location in the middle of the network), on the right side - poor focal coverage (event location near the border of the network). Noise contamination of the input data up to $20 \%$. Hudson plot shows the deviation from the pure DC solution of full MT assumed in preparing synthetic data. Points further away from the centre denote the more significant non-DC components. Bigger nodal plane deviation and spread from pure DC solution on Hudson plot are observed for poor focal coverage

resolved. Therefore, the test was carried out for three different depth levels in all cases. Moreover, take-off angle variability up to $15^{\circ}$ was also verified in every case due to the expected uncertainties of the 1D velocity model. Input amplitudes were perturbed with noise up to $20 \%$ of the initial first pulse Pwave displacement amplitude. For two locations (in the centre and at the edge of the network) and three depth levels, bootstrap amplitude resampling tests of noise and take-off angle uncertainty influence were conducted. Results of the noise impact on MT inversion for Lai Chau network are shown in Fig. 8. Relatively small noise contamination did not affect much the stability of nodal plane solutions. However, it is worth pointing out that the $6-\mathrm{km}$ depth solutions are less stable than the $2-\mathrm{km}$ and $10-\mathrm{km}$ depth solutions, due to the location of the boundary of the velocity model around this depth. It applies for both location cases. Therefore, we can conclude that the focal sphere coverage is not critically sensitive when a nodal plane solution of full MT is taken into account. The error of the solutions was measured as RMS following Stierle et al. (2014a, b). The biggest RMS error in all cases was around 0.2, with mean values of less than 0.1 (Fig. 8). Noise influence is mainly noticeable in spurious non-DC components of the full MT solution showed in Hudson plots (Fig. 8 ), and the focal coverage also plays a role in the relative increase of the non-DC components. The worse focal coverage produces substantial non-DC components with larger spread around the pure DC central point in Hudson plot. The depth of the origin does not influence much the quality of solutions, but the solutions obtained for the $10-\mathrm{km}$ depth were the closest to the pure DC solution in terms of MT decomposition.
The take-off angle bootstrap test results (Fig. 9) show that the focal coverage may play an important role in MT inversion. All solutions obtained for good focal coverage- the case when the event is located in the centre of the network-are much more stable in terms of nodal plane solutions and full MT decomposition. Moreover, RMS values are smaller for good focal coverage in all tested depths, than in case of worse focal coverage for events located close to the network edge. In the latter case, the influence of the take-off angles variability has a similar effect on the MT decomposition as the $20 \%$ noise contamination (Figs. 8 and 9, right panels). On the other hand, non-DC components values in good focal coverage case are usually smaller than those obtained for noise contamination synthetic data, while RMS error has similar values. All the above-described tests were conducted for ten closest stations. However, the software requires at least eight stations, and it is highly probable that not every station will be available all the time after the impoundment. Therefore, a bootstrap test removing randomly one or two stations was carried out to obtain the minimum required number of stations for full MT inversion with up to $20 \%$ noise contamination (Fig. 10). Resampling was performed 100 times. The number of outlying solutions with high nonDC components and nodal planes significantly different than the assumed focal mechanism was relatively small for both focal coverages and all tested depths. However, the good focal coverage solutions were less sensitive on station removal than the seismic station setup for the event from the edge of the network. In the latter case, MT results were characterised with more significant spurious non-DC components and a wider range of the nodal plane solutions - up to $20^{\circ}$ of strike orientation in $95 \%$ of the obtained results. At the same time, up to $10^{\circ}$ range was observed in a good focal coverage case. In both focal coverage cases, particular solutions were utterly different than the assumed one-both in faulting regime (thrust or strike-slip instead of normal) and nodal plane orientations (Fig. 10). Stations with the biggest influence on the proper reconstruction of the nodal planes were MLAV and PUDD being the 


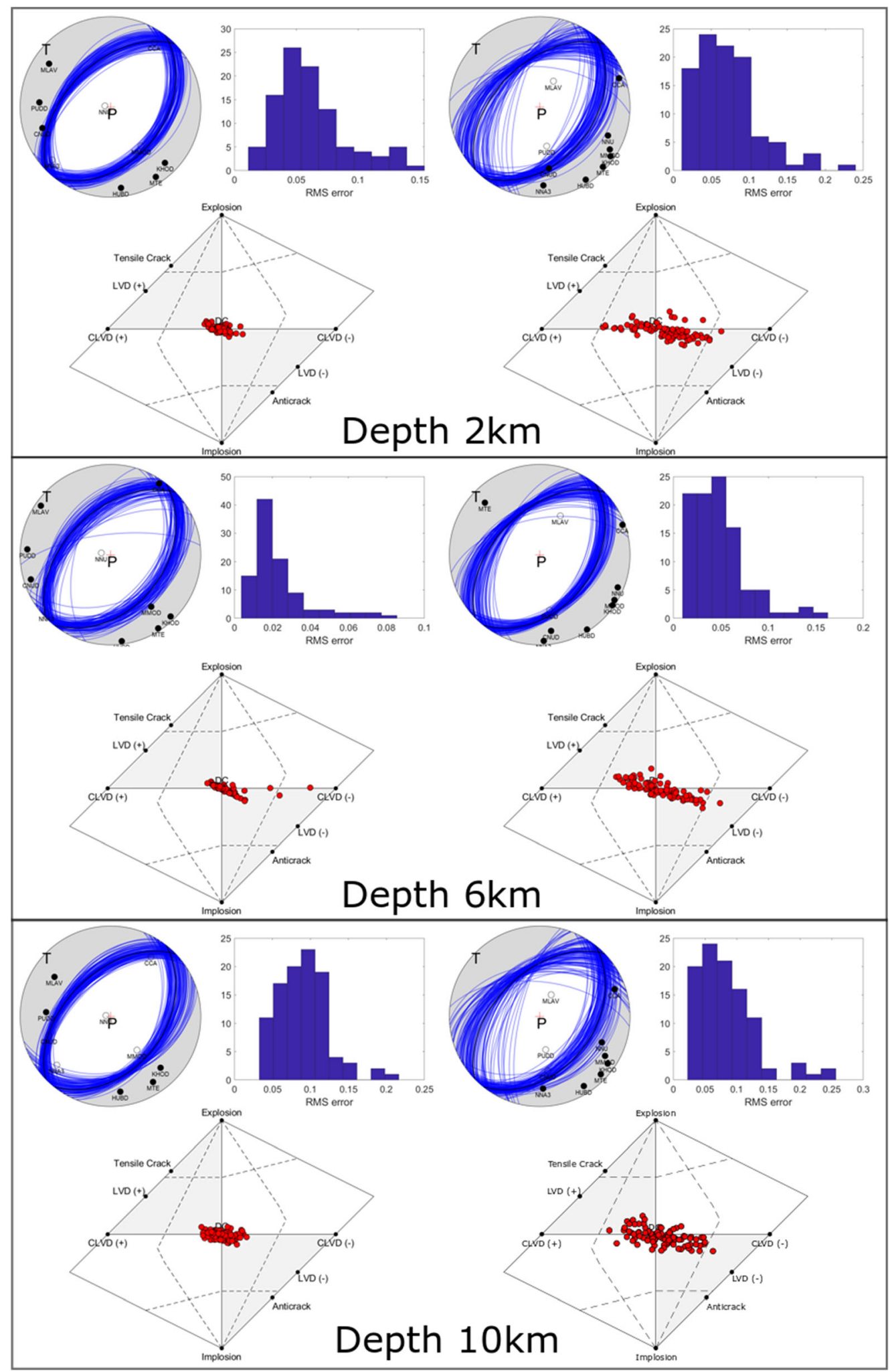


Fig. 9 The take-off angle bootstrap test results of MT inversion for Lai Chau network. Take-off angle variability was set up to $15^{\circ}$. On the left side - good focal sphere coverage, on the right - poor focal coverage. Hudson plot shows the deviation from the pure DC solution of full MT assumed in preparing synthetic data-points further away from the centre denote the more significant non-DC components. Take-off angle uncertainty influence is bigger in case of poor focal coverage on both fault plane solution and full MT components. Nodal planes deviate on the much broader range in case of the event located near the border of the network (beach balls on the right panel). Hudson plot shows the bigger deviation from the pure DC solution of full MT in the same case (right panel)

closest to the source in case of the poor focal coverage and NNU and CCA in case of the good focal coverage. If one or both of these stations were removed, the nodal plane was not correctly resolved. Therefore, in future works, it should be avoided to perform MT inversion when both stations are not available. Station removal test is also recommended for checking the stability of MT inversion in every case when one of these stations is not available for inversion.

\section{Discussion and conclusions}

Background seismicity before the impoundment of Lai Chau was monitored for several months. The observed events are smaller than reported tectonic events for Da river headwaters fault zone, which is the closest active fault zone to the dam site. The reported size of the biggest events for that zone is around M4.6. They were located mainly in close vicinity of Lai Chau dam, but a small number of the events were in the area of Lai Chau-Dien Bien fault zone. The latter were situated between the Nam Nho-Nam Cuoi and MoungTe fault zones, to SW and NW from the dam, respectively (Fig. 5). It indicates that these discontinuities should be considered as the main source of the background seismicity in the Lai Chau reservoir area. Completeness magnitude was estimated at M0.7, while the maximum observed magnitude was M3.1. Average activity of the seismicity was about 0.3 events per day and it varied during the observation period (October 2014-June 2015) from almost 0.4 to 0.23 events per day. The $b$ value of G-R distribution of the magnitude was also estimated with the average value of 0.8 . The $b$ value in tectonic seismicity may differ within a relatively small area due to different stress regimes (Schorlemmer et al. 2005) or pore pressure influence (Bachmann et al. 2012). In the case of Lai Chau region, $b$ value is smaller than the average $b$ value observed for tectonic seismicity on the whole Earth, which is around $1 \pm 0.03$. However, a wide range of $b$ values from 0.3 to 2.5 for different tectonic settings is reported in the literature (e.g. El-Isa et al. 2014 and reference therein). As shown by Pailopee and Choowong (2014) in the area of Southeast Asia, several seismic zones can be distinguished with $b$ value ranging from 0.7 to 1 . In studied area, $b$ value before the impoundment is within the reported range for this region, but lower than the average. The seismic activity in Lai Chau differs significantly from seismic activities in zones investigated by Pailopee and Choowong (2014). More similar $b$ values were obtained for smaller zones including Lai Chau (e.g. Lu et al. 2017) or bordering the region of the Lai Chau dam (e.g. Cao et al. 2019). All these estimates were obtained with catalogues covering large magnitudes, usually $M_{\mathrm{c}}=4$.

Seismic data after impoundment in June 2015 are available until May 2017 with 316 events with magnitude $0.1 \leq M \leq 4.6$ and location of most of the events at shallow depths between 3 and $6 \mathrm{~km}$, which is similar to the state before the impoundment. The spatial distribution of the events is similar (except from the larger number of events in the period after impoundment, which was more than two times longer) to that observed before the impoundment (Fig. 11). The completeness magnitude for the catalogue after impoundment is the same as in the previous period and equals $M_{\mathrm{c}} 0.7$. There were 257 events in the catalogue with magnitudes above the completeness magnitude. There was a decrease of both the seismic activity and the $b$ value after the impoundment until October 2016. Then the activity and $b$ value increased and reached the highest values since the beginning of the observations. If changes of the activity and $b$ value are related to the impoundment, it suggests delayed response of reservoir-triggered seismicity with an increase of seismicity observed more than 1 year after impoundment. Average $b$ value calculated together for both periods before 


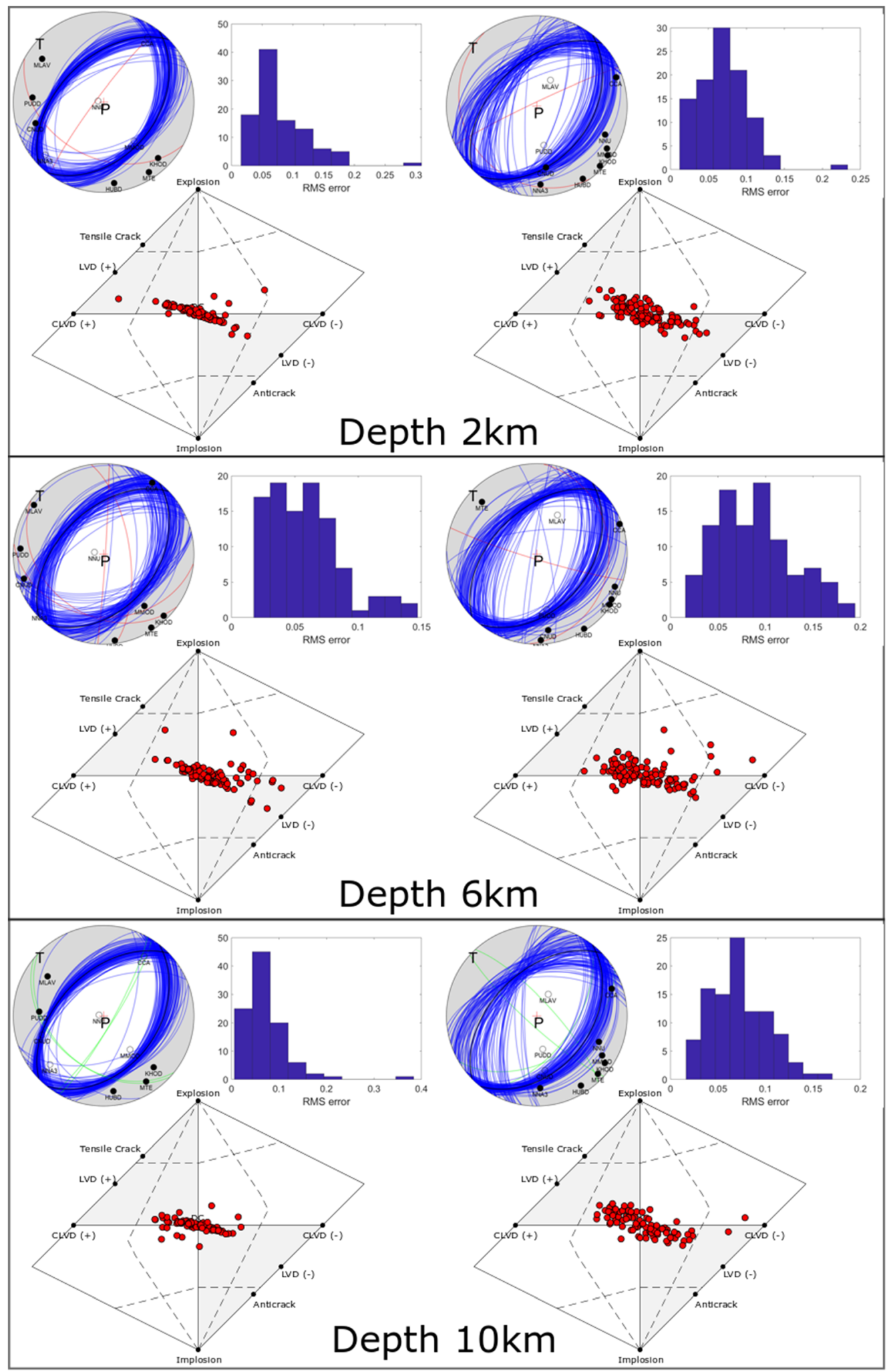


Fig. 10 Station removal of up to 2 stations for one sample and $20 \%$ noise contamination bootstrap test results on MT inversion for Lai Chau network, for the network set up introduced in Fig. 8. Blue nodal planes denote the normal fault, green denotes strikeslip and red thrust faults, respectively. Station removal for the event located near the borders of the network (right panel) influences the result significantly more than in case of the event located in the middle of the network (left panel) in case of the nodal plane solution and full MT. Hudson plot shows the highest deviation from the pure DC solution of full MT in case of the event located near the border of the network (right panel)

and after impoundment is around 0.5, which is much smaller than reported by Pailopee and Choowong (2014) for seismic zones of Southeast Asia. Spatial location of the events in close vicinity to the main faults in the study area (Fig. 11) may indicate their triggering on active faults, which is well-known phenomena in other seismicity triggered reservoirs situated in tectonically active areas like Italy (e.g. Braun et al. 2018; Valoroso et al. 2009). In contrary to these cases, there is no clear correlation of the water level changes and increase in the activity (Valoroso et al. 2009) or the occurrence of the largest events that fits changes in water level (Braun et al. 2018). Therefore, the triggering effect of the reservoir impoundment cannot be confirmed upon the above findings. However, we expect that the triggering effect is possible to be detected when more data are available for further processing.

In general, seismic activity in the region of the Lai Chau dam differs from average seismic activity in larger zones including the dam area (e.g. Pailopee and Choowong 2014; $\mathrm{Lu}$ et al. 2017; Cao et al. 2019). Parameters of $b$ value and completeness magnitude obtained in our work seem to be better suited for testing the variability of seismicity caused by filling the reservoir than those discussed above, due to the lower magnitude completeness and a smaller area of the observation. Seismic activity in the region of the Lai Chau dam is low and the magnitudes were small during the observation period (the strongest event was $M_{\mathrm{L}}=4.6$ ). Low $b$ value means that more big events in comparison to the small ones were observed within available magnitude range. Such low $b$ values may be apparent due to the small number of the events or narrow range and type of magnitudes taken into calculations, and the following uncertainty of completeness magnitude estimation (Deichmann 2017, 2018; Leptokaropoulos et al. 2018).
However, completeness magnitudes (Table 2), corresponding $b$ values obtained for Lai Chau area and small $b$ value uncertainties (Table 3 ) prove that the completeness magnitude is low enough for the proper statistical investigations of the distribution and further examination of possible temporal changes of activity connected with reservoir exploitation.

The network capabilities for detecting and location of the events allow for further analysis after impoundment. Synthetic test results of the P-wave amplitude and polarity MT inversion show that focal mechanism and MT solution of the biggest events should be reliable when some minimum requirements of the quality of the recordings, focal coverage and station number are fulfilled. These requirements are the following: a relatively small noise (about $20 \%$ of the signal amplitude), the event has to be recorded by at least eight stations, the closest stations should be located several kilometres from the epicentre and the focal coverage with big azimuthal gaps should be avoided. Other techniques allowing to calculate full MT, such as full waveform inversion, are also available. It was proved that the local and regional surface networks may be useful in obtaining full MT with the full waveform inversion in case of shallow induced seismic events (e.g. Rudziński et al. 2016; Cesca et al. 2013). They can also be robust for non-DC component determination (e.g. Stierle et al. 2014a). However, the velocity model, network and recording quality requirements are much higher for full waveform inversion (Sen et al. 2013). The P-wave amplitude inversion is more reliable than the waveform inversion method of the calculation of the non-DC components in case of sparse, surface networks (Fojtikowa et. al 2010). Taking this into account, the recordings with small noise could be used even in the case of significant azimuthal gaps for full MT inversion. This may be the case in areas of relatively low seismicity related to reservoir impoundment such as Lai Chau. Noise level and a number of stations available for analysis are the most influencing factors for reliable MT solution in the determination of both nodal plane and MT decomposition in tested setups. Despite the relatively short and limited local seismic monitoring of the Lai Chau reservoir area, the background seismicity and seismic network for Lai Chau reservoir vicinity are established well and form the basis for the further studies of the reservoir impoundment influence on the seismicity in this area. Moreover, the preliminary analysis of the seismic activity after Lai Chau reservoir 

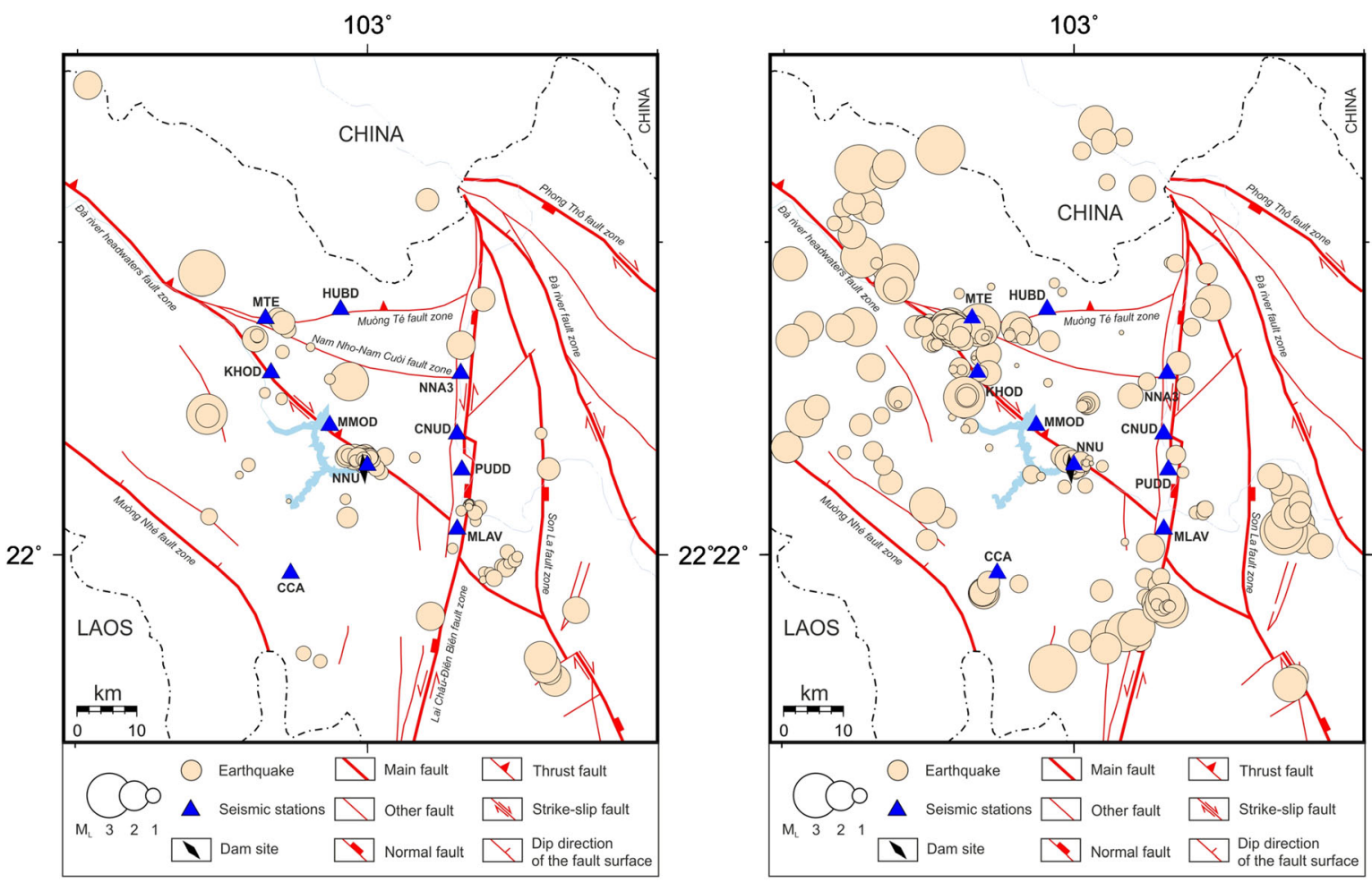

a)

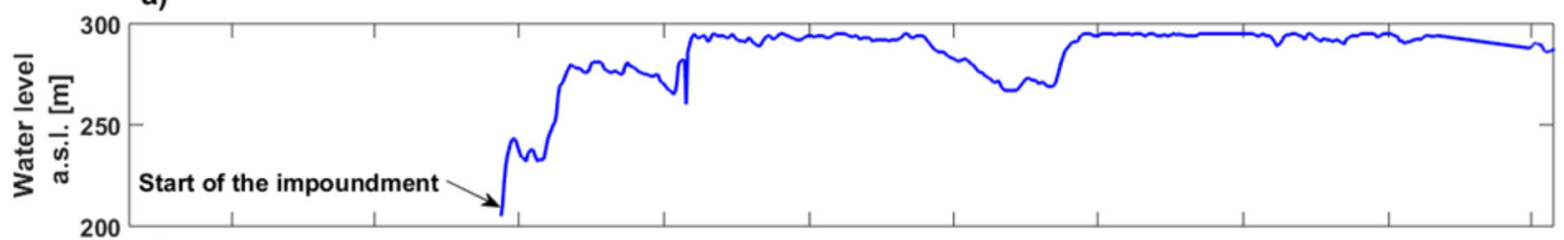

b)
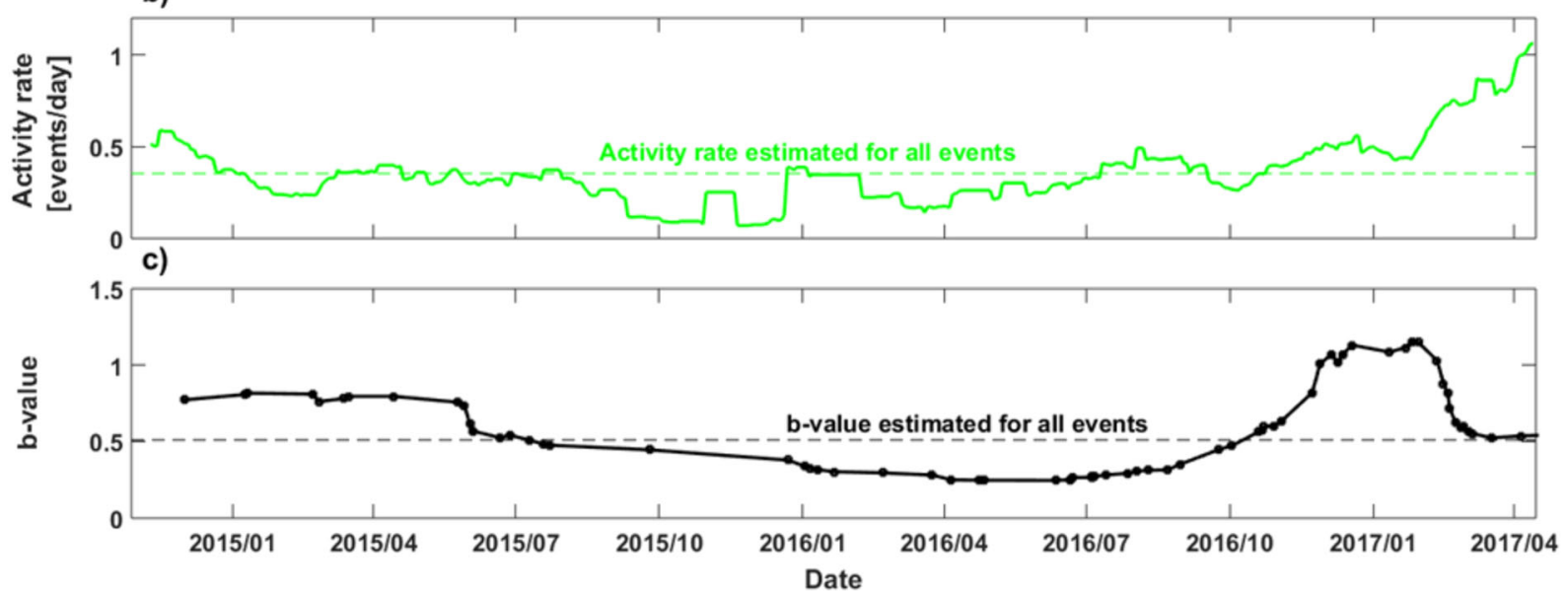

Fig. 11 Map view of event distribution before impoundment (left side) and after impoundment until May 2017 (right side). The temporary seismic activity rates [events/day] (b) and temporary $b$ values of the Gutenberg-Richter magnitude distribution (c) versus water level of the Lai Chau dam (a). The seismic activity rates were estimated in
45 days windows shifted by ten days step. The $b$ values were estimated in windows of an equal number of events ( 50 events). Dots on diagram (c) are located in the middle of the windows. The water level diagram starts with the beginning of the impoundment 
impoundment indicates some changes in activity related to the impoundment and reservoir exploitation.

Acknowledgements We would like to convey sincere thanks to the Vietnam Ministry of Science and Technology for support in providing financial expenditure to implement the research theme of Governmental Science and Technology Project codingĐTĐLCN.27/15.

Funding information Grzegorz Lizurek, Nguyen Van Giang, Beata Plesiewicz and Jan Wiszniowski have been partially supported by research project no. 2017/27/B/ST10/01267, funded by the National Science Centre, Poland, under the agreement no. UMO-2017/27/B/ST10/01267.

Grzegorz Lizurek, Beata Plesiewicz and Jan Wiszniowski were also supported partially within statutory activities No 3841/E-41/S/ 2019 of the Ministry of Science and Higher Education of Poland.

Completeness magnitude estimations and related figures were prepared with the use of the applications available on IS-EPOS platform: https://tcs.ah-epos.eu/\#apps:CompletenessLevelApp.

The seismic catalogue and seismic network metadata files are available on IS-EPOS platform: https://tcs.ah-epos. eu/\#episode:LAI_CHAU.

Open Access This article is distributed under the terms of the Creative Commons Attribution 4.0 International License (http:// creativecommons.org/licenses/by/4.0/), which permits unrestricted use, distribution, and reproduction in any medium, provided you give appropriate credit to the original author(s) and the source, provide a link to the Creative Commons license, and indicate if changes were made.

\section{References}

Aihara K, Takemoto K, Zaman H, Inokuchi H, Miura D, Surinkum A, Paiyarom A, Phajuy B, Chantraprasert S, Panjasawatwong Y, Wongpornchai P, Otofuji Y (2007) Internal deformation of the Shan-Thai block inferred from paleomagnetism of Jurassic sedimentary rocks in Northern Thailand. J Asian Earth Sci 30(3-4):530-541

Aki K (1965) Maximum likelihood estimate of $b$ in the formula $\operatorname{logN}=\mathrm{a}-\mathrm{bM}$ and its confidence limits. Bull Seismol Soc Am 43:237-239 ISSN 0037-1106

Aki K, Richards PG (2002) Quantitative seismology. University Science Books, Sausalito

Bach LD, Tam BM (2008) History of tectonic-magmatic development for Vietnam. Vietnam J Earth Sci 30(4):388-395 (in Vietnamese, abstract in English)

Bachmann EC, Wiemer S, Goertz-Allmann PB, Woessner J (2012) Influence of pore-pressure on event-size distribution of induced earthquakes. Geophys Res Lett 39:L09302. https://doi.org/10.1029/2012GL051480

Bratt SR, Bache CT (1988) Location estimation using regional array data. Bull Seismol Soc Am 78:780-798

Braun T, Cesca S, Kuhn D, Martirosian-Janssen A, Dahm T (2018) Anthropogenic seismicity in Italy and its relation to tectonics: state of the art and perspectives. Anthropocene 21: 80-94. https://doi.org/10.1016/j.ancene.2018.02.001
Brookfield ME (1996) Reconstruction of Western Sibumasu. J Geol Ser B 7-8:65-80

Cao DT, Le VD, Thai AT, Dang TH, Cao DT (2019) The characteristics of seismic activity in the ladder zone of Da river hydro-electric plants. Vietnam J Sci Technol Eng 61(1):8291. https://doi.org/10.31276/VJSTE.61(1).82-91

Cesca S, Rohr A, Dahm T (2013) Discrimination of induced seismicity by full moment tensor inversion and decomposition. J Seismol 17:147-163. https://doi.org/10.1007/s10950012-9305-8

Dahm T, Becker D, Bischoff M, Cesca S, Dost B, Fritschen R, Hainzl S, Klose CD, Kuhn D, Lasocki S, Meier T, Ohrnberger M, Rivalta E, Wegler U, Husen S (2013) Recommendation for the discrimination of human-related and natural seismicity. J Seismol 17(1):197-202

De Natale G, Iannaccone MM, Zollo A (1987) Seismic sources and attenuation properties at the Campi Flegrei volcanic area. PAGEOPH 125(6):883-917

Deichmann N (2017) Theoretical basis for the observed break in $M_{L} /$ $\mathrm{M}_{\mathrm{W}}$ Scaling between small and large earthquakes. Bull Seismol Soc Am 107(2):505-520. https://doi.org/10.1785/0120160318

Deichmann $N$ (2018) The relation between $M_{E}, M_{L}$ and $M_{W}$ in theory and numerical simulations for small to moderate earthquakes. J Seismol 22:1645. https://doi. org/10.1007/s10950-018-9786-1

El-Isa HZ, David W, Eaton WD (2014) Spatiotemporal variations in the b-value of earthquake magnitude-frequency distributions: classification and causes. Tectonophysics. 615-616:111. https://doi.org/10.1016/j.tecto.2013.12.001

Fitch TJ, McCowan DW, Shields MW (1980) Estimation of seismic moment tensor from teleseismic body wave data with application to intraplate and mantle earthquakes. J Geophys Res 85:3817-3828

Gahalaut K, Gahalaut VK (2010) Effect of the Zipingpu reservoir impoundment on the occurrence of the 2008 Wenchuan earthquake and local seismicity. Geophys J Int 183:277-285

Ge S, Liu M, Lu N, Godt JW, Luo G (2009) Did the Zipingpu Reservoir trigger the 2008 Wenchuan earthquake ? Geophys Res Lett 36:L20315. https://doi.org/10.1029/2009GL040349

Giang NV, Marquis G, Minh LH (2010) EM and GPR investigations of contaminant spread around the Hoc Mon waste site, Vietnam. ActaGeophys 58(6):1895-7455. https://doi. org/10.2478/s11600-010-0023-8

Gupta HK (1992) Reservoir induced earthquakes. Elsevier Scientific Publishing Company, Amsterdam

Gupta HK (2002) A review of recent studies of triggered earthquakes by artificial water reservoirs with special emphasis on earthquakes in Koyna, India. Earth-Sci Rev 58:279-310

Hoa TT, Anh TT, Phuong NT, Dung PT, Anh TV, Izokh AE, Borisenko AS, Lan CY, Chung SL, Lo CH (2008) PermoTriassic intermediate-felsic magmatism of the Truong Son belt, eastern margin of Indochina. C R Geosci 340(2-3):112-126

Knopoff L, Randall MJ (1970) The compensated linear-vector dipole. A possible mechanism for deep earthquakes. J Geophys Res 75:1957-1963

Kwiatek G, Martinez-Garzon P (2016) HybridMT MATLAB package for seismic moment tensor inversion and refinement. Seismol Res Lett 87(4):1-13. https://doi.org/10.1785/0220150251

Leptokaropoulos KM, Karakostas VG, Papadimitriou EE, Adamaki AK, Tan O, İnan S (2013) A homogeneous 
earthquake catalog for Western Turkey and magnitude of completeness determination. Bull Seismol Soc Am 103(5): 2739-2751. https://doi.org/10.1785/0120120174

Leptokaropoulos K, Adamaki A, Roberts R, Gkarlaouni C, Paradisopoulou P (2018) Impact of magnitude uncertainties on seismic catalogue properties. Geophys J Int 213(2):940951. https://doi.org/10.1093/gji/ggy023

Lizurek G, Wiszniowski J, Giang NV, Plesiewicz B, Van DQ (2017) Clustering and stress inversion in the Song Trahn 2 Reservoir, Vietnam. Bull Seismol Soc Am 107(6):26362648. https://doi.org/10.1785/0120170042

Lu NT, Rodkin MV, Phuong TV, Phung NQ, Hang TT, Hoan VT (2017) Assessment of earthquake hazard for the northwestern Vietnam from geological and geophysical data using an original program package. J Volcanol Seismol 11(2):164 171. https://doi.org/10.1134/S0742046317020063

Pailopee S, Choowong M (2014) Earthquake frequencymagnitude distribution and fractal dimension in mainland Southeast Asia. Earth Planets Space 66:8. https://doi. org/10.1186/1880-5981-66-8

Peterson J (1993) Observations and modeling of seismic background noise, USGS, Open-File Report 93-322.

Pho NV (2000) Result survey for active fault of Lai Chau hydropower dam area by gas-geochemical method. Report of the preprocess stage. Institute of Geophysics, Vietnam Academy of Science and Technology, Hanoi (in Vietnamese)

Richter CF (1936) An instrumental earthquake magnitude scale. Bull Seismol Soc Am 1-32

Richter CF (1958) The magnitude scale. In: Richter CF (ed) Elementary Seismology, vol 578. Freeman, San Francisco, pp 338-345

Rudziński Ł, Cesca S, Lizurek G (2016) Complex rupture process of the March 19, 2013, Rudna mine (Poland) induced seismic event and collapse in the light of local and regional moment tensor inversion. Seismol Res Lett 87(2). https://doi. org/10.1785/0220150150

Sato K, Liu Y, Wang Y, Yokoyama M, Yoshioka S, Yang Z, Otofuji Y (2007) Paleomagnetic study of Cretaceous rocks from Pu'er, western Yunnan, China: evidence of internal deformation of the Indochina block. Earth Planet Sci Lett 258(1-2):1-15

Schorlemmer D, Wiemer S, Wyss M (2005) Variations in earthquakesize distribution across different stress regimes. Nature 437(7058):539-542. https://doi.org/10.1038/nature04094

Sen AT, Cesca S, Bischoff M, Meier T, Dahm T (2013) Automated full moment tensor inversion of coal mining-induced seismicity. Geophys J Int 195:1267-1281. https://doi. org/10.1093/gji/ggt300

Son LT, Giang HT, Van DQ (2012) Building one-dimensional P-wave velocity model for the northern part of North West Region of Vietnam. J Sci Earth 34(3):243-250 (in Vietnamese)

Stierle E, Vavryčuk VŠ, V and Bohnhoff M. (2014a) Resolution of non-double-couple components in the seismic moment tensor using regional networks - I: a synthetic case study. Geophys J Int 196(3):1869-1877. https://doi.org/10.1093/gji/ggt502

Stierle E, Bohnhoff M, Vavryčuk V (2014b) Resolution of nondouble-couple components in the seismic moment tensor using regional networks - II: application to aftershocks of the 1999 Mw 7.4 Izmit earthquake. Geophys J Int 196(3): 1878-1888. https://doi.org/10.1093/gji/ggt503

Thang TV, Tung VD (2006) Characteristics of the Pliocene quaternary neotectonics in Northwest Vietnam region. Journal of Sciences, AP "Sciences of the Earth", Vietnam National University Hanoi, 30th anniversary of establishment of the Geological Faculty, T.XXII, N0 2A, 86-99.

Tong Y-B, Yang Z, Zheng L-D, Xu Y-L, Wang H, Gao L, Hu X-Z (2013) Internal crustal deformation in the northern part of Shan-Thai Block: new evidence from paleomagnetic results of Cretaceous and Paleogene redbeds. Tectonophysics 608:1138-1158

Tung NT (1996) The induced seismicity at Hoa Binh Reservoir region, Abstract Vol. IASPEI Reg. Assembly in Asia, Tangshan, China, Aug 1-3

Tung VD (2011) Development characteristics of the Lai Chau Dien Bien fault zone. Geological Doctoral Thesis. Institute of Geological Sciences, Vietnam Academy of Science and Technology, Hanoi (in Vietnamese, abstract in English)

Valoroso L, Improta L, Chiaraluce L, Di Stefano R, Ferranti L, Govoni A, Chiarabba C (2009) Active faults and induced seismicity in the Val d'Agri area (Southern Apennines, Italy). Geophys J Int 178: 488-502. https://doi.org/10.1111/j.1365-246X.2009.04166.x

Vavryčuk V (2001) Inversion for parameters of tensile earthquakes. J Geophys Res 106(B8):16339-16355. https://doi. org/10.1029/2001JB000372

Vavryčuk V (2015) Moment tensor decompositions revisited. J Seismol 19(1):231-252. https://doi.org/10.1007/s10950-014-9463-y

Waldhauser F (2001) HypoDD: A computer program to compute double-difference earthquake locations. USGS Open File Rep 01-113:2001

Wiejacz P (1992) Calculation of seismic moment tensor for mine tremors from the Legnica-Głogów Copper Basin. Acta Geophys Pol 40:103-122

Wiemer S, Wyss M (2000) Minimum magnitude of completeness in earthquake catalogs: examples from Alaska, the Western United States, and Japan. Bull Seismol Soc Am 90(4):859869 ISSN 0037-1106

Wiszniowski J, Giang NV, Plesiewicz B, Lizurek G, Van DQ, Khoi LQ, Lasocki S (2015) Preliminary results of anthropogenic seismicity monitoring in the region of Song Tranh 2 Reservoir, Central Vietnam. Acta Geophys 63(3):843-862

Wyss M, Hasegawa A, Wiemer S, Umino N (1999) Quantitative mapping of precursory seismic quiescence before the 1989, m7.1 off-sanriku earthquake, Japan. Ann Geofis 42(5):851-869

Yang ZY, Besse J, Sutheetorn V, Bassoullet JP, Fontaine H, Buffetaut E (1995) Lower-Middle Jurassic paleomagnetic data from the Mae Sot area (Thailand): paleogeographic evolution and deformation history of Southeastern Asia. Earth Planet Sci Lett 136(3-4):25-341

Zechar JD (2010) Evaluating earthquake predictions and earthquake forecasts: a guide for students and new researchers, Community Online Resource for Statistical Seismicity Analysis. https://doi.org/10.5078/corssa-77337879

Publisher's note Springer Nature remains neutral with regard to jurisdictional claims in published maps and institutional affiliations. 